\title{
STUDIES IN THE PHYSIOLOGY AND PSYCHOLOGY OF THE TELEGRAPHIC LANGUAGE.
}

\author{
BY PROFESSOR WILLIAN LOWE BRYAN AND MR. NOBLE \\ HARTER. 1
}

Indiana University.

In March, I893, Mr. Harter began at the Psychological Laboratory of the Indiana University a study of certain problems connected with the acquisition of the telegraphic language. Eleven months were spent at and away from the University in a preliminary study of these problems, in the light of his own experience, and by diligent, personal cross-examination of thirty-seven operators, employed by the Wabash Railway Company and by the Western Union Telegraph Company. Of these, seven were recognized as experts, twenty-two as men of average experience and ability, while eight had barely enough skill to hold their places. Twenty-eight of the number had been personally known to $H$. from two to sixteen years. Throughout these and the subsequent investigations, the mem bers of the telegraphic fraternity showed the most cordial interest and readiness to help.

In March, I894, H. began at the University Laboratory, an experimental study of individual differences in telegraphic writing. The experimental part of this study continued until August, r894, and the study of the results until June, I895. A review of certain phases of the results was made in January, 1896. During the winter of $1895-96$ he was engaged with the study of the curve of improvement in sending and receiving.

\section{The Prelminary Study.}

The first year's work was in the nature of an exploring expedition in search of the problems which would repay fuller in-

${ }^{1}$ N. H., a graduate student of Psychology at Indiana University, was for many years a railroad telegrapher, and is an expert in that branch of telegraphy. The experiments were made under Professor Bryan's direction. 
vestigation. It seems best, on the whole, to give a somewhat gossipy, through brief account of this exploration. The method of exploration consisted in cross-examining the operators with questions which, on the one hand, seemed to have psychological or physiological significance, and which, on the other hand, in the light of H's personal experience, gave promise of answers.'

The student learns to distinguish most of the letters of the telegraphic alphabet in a few hours or days at most; but after distinguishing them clearly at one time, he generally finds himself confused by the back stroke, and must re-learn the letters many times before this difficulty is overcome. The back stroke is the stroke of the armature against the adjusting screw above it. Those letters composed of simple dots or dashes are mastered first, then those composed of dots and spaces, and lastly those most complex, as, J ( _. - .), X (. _..) Q(..-.).

As the characters composed of four, five and six dots, are made more rapidly than the learner is able to count, much practice is necessary before he can recognize surely the number of dots in such groups. When a considerable degree of speed in receiving is reached, the space between the letters of a word becomes so small that one ceases to recognize it consciously, the letters seem to blend together, and the word is recognized as a sound whole. Thus, expert operators read zerds from their instruments; and, as will be seen later, these group themselves into larger wholes, so that the sentence becomes the conscious unit, much as in the reading of printed matter. Of course, the short and frequently recurring words are the first ones to have their parts melt together. A learner is thus very soon able to distinguish such words as, 'the,' 'is,' 'and,' etc., when written swiftly on the main line in their proper connection, while he cannot understand even a single letter in other words. This observation shows that a given group of sounds, for example those making the letter $\mathrm{H}$, may be apperceived in one instant because occurring within a larger known group, and then not apperceived a moment later because occurring as part of an unknown group.

2 To save circumlocutions, technical words in common use among telegraph operators and whose meaning is plain, will be used in this article. 
There are distinct specialties in telegraphy, so that while an operator may be competent in one department he would be a failure in another department requiring no greater speed, until he had acquired the vocabulary of that department. Thus, a commercial operator would be 'lost' in a yard office, or the train dispatcher in taking markets. It is the opinion of experienced operators that while there are many exceptional cases of quickness and slowness in learning, ${ }^{1}$ it requires from two to two and a half years to become an expert operator. Through lack of energy to practice, except when compelled by the nature of their work, few operators reach their maximum, while many have little more than the skill actually required in their daily work. To gain expertness, work increasing in difficulty must be faithfully done. For a fuller discussion of this point see below, part IV.

The effect of sending a long strange word swiftly is to cause the receiver to make an error or break-that is, to ask for a repetition of the word. Many operators are very sensitive on the subject of breaking, and some do not hesitate to supply the most probable word and thus avoid what they consider a humiliation. Sometimes an obnoxiously smart young operator is allured through his pride against breaking, into a trap, whose psychology is significant. The date and address of a message are sent at a rapid rate, followed by the period which separates the address from the body of a message. The letters of the alphabet in order are then plainly but rapidly sent to him. The receiver expects a message. In the first few letters he recognizes no word group. He hopes to see the connection a little farther on. He is finally compelled to break. It is sometimes possible to repeat this trick several times without the victim discovering it. In this case evidently the strenuous effort of attention to recognize word groups has prevented the recognition of a most familiar group, namely, the alphabet in order.

Another interesting apperceptive illusion, to which even ex-

${ }^{1}$ A story is told of an Indiana operator, who, after three months' practice, was able to receive Garfield's Inaugural Address. Stories of this sort must be taken with a grain of salt. The more of telegraphy you know, the more salt it takes. 
pert operators are subject, arises in the following way: The adjustment of the armature of the sounder is controlled by set screws so that the down stroke and up stroke may be differentiated. The down strokes, of course, correspond to the dots and dashes of the Morse code. Whether a dot or dash is intended, is determined by the length of time between the down stroke and the following back stroke. It is evidently essential that the down stroke and the back stroke should he clearly distinguishable. Making this distinction is one of the greatest difficulties in learning telegraphy. The student may learn to recognize several of the simple dotted letters in a few minutes; yet after an hour, when $\varepsilon$, a single dot, is made, he interprets the two sounds which he hears as $i$, which is two dots. Learners seek to assist the ear by watching the teacher's hand or the armature of the sounder. This device must, of course, be prohibited, and the learner required to depend on the ear alone. Several instances have been observed in which expert operators have made the same sort of error when listening to strange instruments in which the down stroke and back stroke were not very clearly different. In such cases the experts were unable to understand even a single letter. By a sort of inversion of attention the back strokes are heard as down strokes, and vice versa.

The rate of receiving varies greatly. On train wires, about twenty to twenty-five words, of four letters each, per minute, may be taken as the ordinary rate of communication. Among lower grade operators the ability to send is greater than the ability to receive, but with experts the reverse is generally true. The highest sending record, so far as known, is fortynine words per minute. When the type-writer is used the ability of the receiver exceeds that of the sender. Words in cipher cannot be received so rapidly or so accurately as ordinary language. The telegraph companies recognize this fact by charging very high rates for combinations of letters forming other than ordinary English words. Errors in the transmission of messages are comparatively few, and it is the common feeling of telegraphers that they could testify more surely in Court concerning what they have heard on the line than concerning what 
they have heard from personal interview, or as to the accuracy of a message which they have copied from a sounder than as to one which they have copied from dictation.

External disturbances have a very great effect upon inexperienced operators, but affect the experienced operator very little. It is not uncommon to see an operator doing a large amount of important work in a small room where half a dozen sets of instruments are working, trainmen running in and out, talking excitedly and asking questions, engines moving by the window and trucks running noisily by on the platform. Yet the operator works ahead, calmly and rapidly, and even briefly answers questions addressed to him. Where a number of sounders work close together, pieces of tin, brass or the like may be attached so as to give each a distinguishable tone. Many men can receiye from an instrument adjusted low in the presence of others sounding much louder. The ability to do this, however, is much lessened by lack of practice. Dispatcher $C$. was a copyer for several years in an office where he worked with several instruments close together. After he had been promoted two years to a dispatcher's desk, where but one instrument was used, he lost the ability to do the work he had formerly done, being confused by the working of the other instruments.

Subjective disturbances, as fear, anger, excitement, etc., have little effect on expert men other than to make them more fluent in the use of the telegraphic language. Operators are keenly alive to the presence of those with whom they communicate, so that they do not feel alone, although no one is physically present. This feeling causes young operators to suffer keenly from stage fright, especially when making their debut. The first work generally consists in reporting a train to a dispatcher. The debutant is very anxious to do so, and practices hard so as to do it well, but almost invariably does it in such a manner as to attract the attention of all the operators on the line. It is not unusual to see a beginner sweating profusely in a cold room from the exertion of taking an easy ten-word message. A similar fact appears in the difficulty which the young operator has to keep up a conversation. He writes very slowly, and 
yet he cannot think of enough things to say. The organizing imagination seems paralyzed by the presence of his audience. In one who is not an expert the emotions of fear, of anger and even of joy, generally paralyze invention, so that only spasmodic or meaningless sound groups can be made, and every one recognizes that the man is 'rattled.' The ability to receive is also often so affected that he is unable to recognize anything. This is particularly true in the case of fear.

The telegraphic language becomes so thoroughly assimilated that thinking apparently resolves itself into the telegraphic short hand used in conversation. This telegraphic short hand is an abbreviated code in which the vowels and many consonants are thrown out. One thinks in telegraphic terms. An odd expression or an unusual message attracts the operator's attention, while he is directly engaged with some other work. Operators who work at night depend on their office call to waken them. The sensation is that of hearing one's name repeated softly over and over. When the operator is worn out by loss of sleep or physical fatigue he is, of course, more difficult to awaken. At such times the sender writes the office call very distinctly and makes unusually long spaces. This seems to add emphasis to the call. The anger flutter, a whir made by rapid alternate strokes of the first and second finger, is also employed with good effect to awaken sleeping telegraphers.

How thoroughly the telegraphic language is mastered in some cases is illustrated by the fact that expert operators 'copy behind' three or four words; sometimes ten or twenty words; that is, the receiving operator allows the sender to write a number of words before he begins to copy. It is then possible for him to get something of the sense of the sentence in advance. The operator is thus able, not only to punctuate and capitalize, but also to keep run of the grammatical structure. Yet, while he would detect an error, or notice that a word was not appropriate in the connection used, and be able to suggest to the sender what the word should be, the language of the message as a whole may have little or no meaning to him. Several cases illustrating this fact have been observed. The most notable case was given by Chief S. A message for the superintendent 
was received by a very skillful operator. Any one might have seen from its contents that it required immediate delivery and action. Some word in the message had been so written that it was misread and missent by the sending operator. The receiving operator saw that this word did not make sense, and suggested to the sender that it might be another word similar in appearance. The sender decided that this was true and the message was corrected accordingly. The receiving operator placed the message upon the superintendent's hook, where it was found by a clerk too late for the action required. The receiver could not believe that he had received such a message until his copy was shown him. The details described were then recalled. The railway companies recognize this tendency to automatism by requiring dispatchers not to send out train orders until they have been assured by the operator to whom the orders are sent that he has displayed the proper signals.

The most striking example of complete mastery of the telegraphic language is seen in the daily work of a train dispatcher on a trunk line. Except when there is a very unusual amount of traffic, the dispatcher records the movements of trains as reported on a train sheet, figures on a special meeting point for trains, sends out the order, and as it is repeated by one office, copies it in the order book, checks it again as the next office repeats it, acknowledges its correctness and gives his official sanction; but while this very important work is being done, he figures on other meeting points in which the weather, length of side tracks, size and heaviness of trains, grades and probable delays are items. By the time the first order is completed, he has decided on the next line of action, and so it goes on for the eight hours he is on duty.

When not influenced by nervous diseases, practice enables nearly all to make groups of four, five or six dots with great rapidity. For the accuracy with which this is done see below part IV. Measurements made with the chronograph showed this rate to be as high as twelve dots per second. Letters forming words are written much more rapidly and with greater precision than letters taken at random. The same is true of words in connected discourse as compared with words in random order. 
The effect of emotion upon sending is to give greater facility of expression to expert men, while beginners are in a greater or less degree paralyzed. The syllable ' ha' repeated, indicates laughter and is frequently used without any other external sign even when the operator's risibles are considerably excited. The uninitiated spectator might not suspect that the conversation was humorous. On the other hand, the anger flutter described above is invariably accompanied by a strong facial expression of passion.

Tests were made to ascertain the average rate of sending. The best results were obtained from two one-minute trials of dispatcher $\mathrm{K}$. At the first trial he wrote thirty-nine words of a hundred and eighty-six letters, making four hundred and sixteen impacts upon the key. At the second trial he wrote fortytwo words of a hundred and ninety-two letters, or four hundred and twenty-nine impacts. This shows a speed of seven and twotenths movements per second. If the words in the Cincinnati contest, where the winner wrote forty-nine words per minute, averaged as many impacts per word as in the above cases, the rate would be eight and one-tenth impacts per second. Comparison of these results with the maximum rate of voluntary movement as determined by Von Kries, ${ }^{1}$ Dressler $^{2}$ and Bryan ${ }^{3}$ must, of course, take into account the important differences between the conditions in the tests made.

Every operator develops a distinctive style of sending so that he can be recognized readily by those who work with him constantly. (See III. below.) Mr. S., a dispatcher of much experience, works daily with forty or fifty men and states that, after hearing four or five words, he can readily recognize the sender, or be sure that he is not one of his men. Where two or more operators work in the same office they sometimes change before the appointed time, or work for each other without permission. When a train is reported, however, in such cases, the dispatcher often asks where the other operator is. Operators who feel secure in the seclusion of their offices have

${ }^{1} \mathrm{Du}$ Bois Reymond, Archiv f. Physiologic, 1886. Suppl. I.

Am. Jour. Psychol., IV., p. 514.

sin. Jour. Psychol., V., p. I. 
sometimes been detected in making improper and impertinent remarks on the line, by their style of sending. Two instances were noted where men were discharged for offenses detected in this manner. Young operators have a peculiar way of grouping the letters of words, which gives the impression of some one walking unsteadily as when partially intoxicated. Many dispatchers claim that they can generally recognize a woman by her style of sending.

The best time to learn telegraphy is doubtless before the age of eighteen. The most expert operators have learned as a rule, when quite young. It is very difficult and often impossible to become even a passable operator, when the start is made after thirty. While extreme age weakens and limits the power of the operator, the maximum skill seems to be retained up to the age of sixty-five. This point, however, demands special investigation. Severe headaches and other painful diseases interfere with the work of the operator. Mr. S., now a train master, regards the use of tobacco as hurtful to operators. $\mathrm{Mr}$.W. a Western Union Superintendent thinks tobacco invariably injurious to his men. Many operators do not consider a moderate use of tobacco as detrimental. All agree, however, that intoxicants make a man not only unreliable, but dangerous. To be found in a saloon means discharge on many railroads. The work of telegraphers is much affected by nervous diseases. Writers' cramp frequently disables the sending arm, and causes the retirement of the operator, unless he learns to send with the other arm, a difficult matter with most men so afflicted. Sometimes rest and treatment relieve this difficulty, at least temporarily. Mr. Y. had suffered from a nervous affection which made it difficult for him to stop when making four or five successive dots. He would make ten or twelve dots in writing letters composed of these groups.

\section{Individual Differences in Telegraphic Writing.}

The telegraphic language is singularly well adapted to the experimental study of many problems in physiology, phychology and even philology. Indeed, if one were required to invent a generation-long experiment for the exact study of certain phases 
of language, one could scarcely hope to find a better; for, on the one hand, no other language used by man can be so completely translated into exactly measurable symbols; while, on the other hand, the manifold personal differences in the operators are shown by investigation to be represented in those symbols. As illustration and proof of these assertions, the following study of individual differences in telegraphic writing is offered.

Apparatus.-The DuPrez signal was adjusted to write upon the Marey drum, being carried transversely by the automatic carriage which Verdin supplies with the Marey drum. The Marey chronograph in circuit with the Kroneker Interrupter gave the time control.

The experiment.-The sentence, "Ship $36_{4}$ wagons via Erie quick," was written by each subject about a dozen times in succession. This sentence was chosen because it contains almost every sort of difficulty which the telegraphic language presents. 'Ship' is composed of groups of three, four, two and five dots. Each of the figures $3,6,4$ is somewhat difficult, especially the 6 , which is composed of six dots. 'Wagons' contains two letters which have two dashes in succession. 'Via' is a simple word presenting no special difficulty'. 'Erie' is by far the hardest word in the sentence. By a little change in the time relations, one would get oye, erc, sic, eeye. Such words are usually written with extra care and with longer spaces. The word 'quick' has several dashes, of which the last one is likely to be longer than the others, since it closes the word and the sentence. The sentence as a whole is as follows: $\mathrm{S}(\ldots), \mathrm{h}(\ldots), \mathrm{i}(\ldots) \mathrm{p}(\ldots),. 3(\ldots-),$. $(\ldots \ldots), 4(\ldots-)$, w (.- - ), a (.-), g(- - ) , o (. .), $\mathrm{n}(-),. \mathrm{s}(\ldots), \mathrm{v}(\ldots-)$, i $(.$.$) , a (.-), \mathrm{E}(),. \mathrm{r}(. .$.$) ,$ i $(.$.$) , e ($.$) , q (\ldots-$.$) , u (\ldots-)$, i $(.$.$) , c (\ldots)$, k $(-.-)$.

The subjects.-By connecting the Du Prez signal with the main lines of the Western Union Telegraph Company and of the Monon Railroad Company, about sixty operators were tested. It was found that it would require several years of continuous work to investigate all of these records by the method decided 
upon. Accordingly sixteen of the number were selected, some of them being expert, some ordinary and some poor operators. Following is a brief characterization of the men, grouped somewhat in the order of their ability as telegraphers, beginning with the less expert. A. B. Guthrie, student I. U., age $2 \mathrm{r}$, 5 months' experience as student in a telegraph office; C. G. Mallotte, student I. U., age 22, 2 years' experience as student in an office, 3 months in charge of a small office; Prof. G. E. Fellows, department of European history, I. U., age 43,5 years' experience in charge of railroad office about I 3 years ago; R. C. Brooks, student I. U., age $2 \mathrm{I}, 3$ years' experience in charge of an office; L. A. Clark, agent Monon, Crawfordsville, Ind., age 40, experience 17 years; C. L. Buchanan, agent Monon, Ellettsville, age 57 , experience 25 years; G. W. Dyer, agent Monon, Bainbridge, Ind., age 6o, experience 33 years; Geo. H. Godfrey, Manager W. U., New Albany, Ind., age 55, experience 3 I years; Mrs. Z. M. Apple, Manager W. U., French Lick Springs, Ind., age 24 , experience 5 years; Miss Nellie Green, operator Monon, Louisville, Ky., age 24, experience 5 years; A. B. Evans, Manager W. U., Bloomington, Ind., age 27 , experience Io years; Noble Harter, graduate student of Psychology, Indiana University, age 37, experience 2 I years; C. W. Goodman, dispatcher, Monon, age 32, experience $I_{5}$ years; H. O. Chapman, dispatcher, Monon, age 27, experience ro years; W. H. Fogg, dispatcher, Monon, age 26, experience ro years; E. B. Cassell, chief dispatcher, Monon, age 36 , experience 8 years.

Measurement of Results.-Each character in the tracings obtained was measured. There are one hundred and forty-nine characters to be measured if the sentence is written without error; but, as in many cases, too many characters were made, the actual number to be measured was considerably greater. Eight repetitions of the message by each of the sixteen subjects were measured, so that the total number of measurements made was about twenty thousand, and required several months. The measurements were made to the nearest half millimetre. The rate of the drum was so adjusted that forty-seven mm. correspond to one second of time. Most of the errors must then evi- 
dently be less than five thousandths of a second, and an error of $1 / 2 \mathrm{~mm}$. would be about one hundredth of a second. Higher accuracy could have been obtained easily, and was obtained in individual cases by increasing the rate of the drum and so lengthening the lines to be measured. But upon careful consideration, the degrees of accuracy given was proved to be sufficient for the experiment proposed.

Methods of Treating Rcsults. - Several methods of treating the results were employed for the purpose of bringing out different points.

First Treatment.-The theoretical Morse alphabet is composed of the following elements: $A$, the dot, one unit of time; $\mathrm{B}$, the dash, three units of time; $\mathrm{C}$, the short space between the parts of a letter, one unit of time; $D$, the long space, in spaced letter, two units of time; $\mathrm{E}$, the space between letters, three units of time; $F$, the space between words, six units of time. This is the ideal scheme which each operator has tried to learn. Now it is possible to compare the actual writing of each individual with this ideal scheme by taking the actual length of his dot as a unit and by then computing the actual ratios of the other elements to this unit. This computation was made for each individual. The average length of dot, dash, etc., being used. The results are given in Table $\mathrm{I}$.

It was found by a study of the individual results that the several values of a given character are not accidental variations from their average value, but that there are constant differences between the times required for the same character in different parts of the sentence or even of the same word. These facts, which affect the value of Table I., will be considered further on. The table proves its value in spite of this or any other defect, however, by the fact that it affords a means of identifying any one of the individuals represented in it. If a single one of the sentences written by one of the subjects be treated by the method employed in constructing the table, a comparison of the several ratios obtained and their sum with the values given in Table I., will in every case show a correspondence so much more exact with one of the sixteen than with any of the others, that the identification will be beyond question. 
TABLE I.

\begin{tabular}{|c|c|c|c|c|c|c|c|}
\hline Name. & A & B & $\mathbf{C}$ & $\mathrm{D}$ & $\mathbf{E}$ & $\mathbf{F}$ & Total. \\
\hline IDEAx CODE & 1.00 & 3.00 & $1 . \infty$ & 2.00 & 3.00 & 6.00 & 16.00 \\
\hline C. G. Mallotte . . . & 1.00 & 1.95 & 1.13 & 1.55 & 1.76 & 2.09 & $9 \cdot 4^{8}$ \\
\hline A. B. GuThrir . . . . & $1 . \infty$ & 4.66 & 2.33 & $3 \cdot 51$ & 5.80 & $7 \cdot 44$ & 24.74 \\
\hline R. C. Brooks. . . . . & $1 . \infty$ & 3.02 & 1.18 & 2.41 & 2.88 & 4.05 & 14.54 \\
\hline G. E. Fzllows. . . . . & 1.00 & $3 \cdot 47$ & 1.24 & 3.09 & $5 \cdot 3^{2}$ & 6.76 & 20.88 \\
\hline A. B. Evans $\ldots \ldots$ & $1 . \infty$ & 2.30 & .89 & 1.98 & 2.10 & 2.65 & 10.92 \\
\hline Noble Harter..... & $1 . \infty 0$ & 2.83 & .95 & $2 \cdot 31$ & 3.08 & 6.44 & 16.61 \\
\hline G. W. DYzR . . . . . & $1 . \infty$ & 2.85 & 1.09 & 2.20 & 2.93 & $5 \cdot 37$ & 15.44 \\
\hline G. H. GODFREY. . . . & $1 . \infty 0$ & 2.27 & .76 & 1.77 & 2.02 & 4.15 & 11.97 \\
\hline C. L. Buchanan . . . & $1 . \infty$ & 2.64 & $\mathrm{r} .02$ & 1.86 & 2.50 & 4.68 & 13.70 \\
\hline L. A. Clark . . . . & $1 . \infty$ & $2.3^{8}$ & .70 & 2.31 & 2.95 & 4.91 & 14.25 \\
\hline Z. M. APPLE . . . . & 1.00 & 2.45 & .94 & I.77 & 2.45 & $3 \cdot 5^{8}$ & 12.19 \\
\hline Nelifie Green . . . . & $1 . \infty$ & 2.49 & .85 & 1.81 & 1.92 & 2.87 & 10.94 \\
\hline W. H. FOGG, . . . . & $1 . \infty$ & 2.98 & 108 & 2.40 & 2.71 & 3.00 & 13.17 \\
\hline E. B. Cassell . . . . & $1 . \infty$ & $2.6 \mathrm{I}$ & 1.06 & 2.23 & 3.01 & 4.12 & 13.92 \\
\hline C. W. Goodman . . . & $1 . \infty$ & $2 \cdot 3^{2}$ & .87 & 2.13 & $2.4^{2}$ & 3.14 & 11.88 \\
\hline H. O. Chapman. .... & $1 . \infty$ & 2.50 & .94 & I.97 & 2.87 & $3 \cdot 3^{6}$ & 12.71 \\
\hline
\end{tabular}

In order to obtain average values which should represent more homogeneous values and also to show characteristic individual differences in a single short and easy word, the results for the word 'via' were treated in the following way. As above, each man's average dot for the six dots in the word was taken as the unit, and the length of each character was computed as a per cent. of that unit. The ideal scale is given for comparison, also, the variation of this average dot from the typical dot, $i . e$, the average of all the dots in the sentence.

In order to prove the identifying value of this table, two tests were made: A friend selected single records from three of the operators. Computations of these records by the same method as that used in making the table gave results which could be unmistakably identified. Then, records of three others were measured from the original tracings and the results 
TABLE II.

\begin{tabular}{|c|c|c|c|c|c|c|c|c|c|c|c|c|c|c|c|c|c|c|c|c|}
\hline & $\stackrel{\text { A }}{\bullet}$ & C & $\stackrel{A}{\circ}$ & C & A & C & B & E & A & C & A & E & A & C & B & $F$ & Total. & $\begin{array}{c}\text { Dot } \\
\text { or } \\
\text { Unit. }\end{array}$ & $\mid \begin{array}{c}\text { Typi } \\
\text { cal } \\
\text { Dot }\end{array}$ & Var. \\
\hline G. Malizotte & 1.07 & I.II & .93 & 1.22 & 1.22 & 1.22 & 2.51 & 1.47 & .93 & I. .00 & .93 & I. 97 & .89 & 1.07 & 2.29 & $2 \cdot 3^{6}$ & 22.19 & 2.79 & 3.05 & .26 \\
\hline A. B. Guthirie & I.19 & 2. 10 & I. IO & 1.95 & $.7 I$ & 2.24 & 4.86 & 4.00 & $.8 \mathrm{I}$ & $\mathrm{x} .76$ & 2.24 & 4.67 & .95 & I.86 & 4.33 & 6.14 & 40.91 & 2. 10 & 1.92 & .18 \\
\hline R. C. Brooks. & .85 & I.32 & 1.06 & 1.28 & 1.32 & I. 36 & 2.60 & 2.13 & .85 & 1.19 & 1.06 & 3.67 & .85 & 1.02 & 4.04 & 5.06 & 29.06 & 2.35 & 2.45 & .10 \\
\hline G. E. Fellows & 1.07 & 1.23 & $1 . \infty 0$ & $\mathrm{x} .29$ & .89 & .87 & 3.99 & 6.32 & 1.07 & I. 26 & 1.03 & 5.16 & .96 & 1.12 & 3.52 & 6.49 & 37.29 & 3.02 & 2.97 & .05 \\
\hline A. B. Evans & .95 & .86 & .90 & .72 & .90 & .99 & 2.52 & 1.44 & I. I 2 & 1.04 & I. 22 & 2.25 & .90 & .95 & $3.1 \mathrm{I}$ & 2.93 & 22.80 & 2.22 & 2.39 & .17 \\
\hline NOBLE HARTER & .76 & 1.03 & I.2I & 1.03 & I. .35 & I. 10 & 3.11 & 2.59 & .83 & 1.03 & I.10 & $2.4^{8}$ & .76 & 1.00 & 3.42 & 6.69 & 29.53 & 2.90 & 3.12 & .22 \\
\hline$G$ W DYPR & .91 & x.16 & I.19 & 1.03 & 1.23 & I. 03 & $2.8 \mathrm{I}$ & 2.08 & .91 & I. 30 & $\mathrm{I} .04$ & 2.80 & .68 & I.OI & $3 \cdot 43$ & 6.54 & 29.15 & 3.07 & 3.28 & $.2 x$ \\
\hline . & .92 & .95 & .95 & .95 & I. IO & .83 & 2.38 & I. ro & .89 & .86 & I. 19 & 2.09 & .92 & .74 & 2.69 & 4.09 & 22.65 & 3.35 & $3 \cdot 72$ & .37 \\
\hline L. BuchanaN & .96 & .99 & I.2I & 1.02 & I.II & 1.21 & 2.82 & .96 & 1.05 & 1.08 & 1.08 & I. 48 & .59 & I.II & $4 \cdot 37$ & $4 \cdot 3 I$ & $25 \cdot 35$ & 3.23 & 3.44 & .21 \\
\hline A. Clark & .9I & .59 & I. 13 & $\mathrm{r} .06$ & 1.00 & .85 & 2.70 & I.9I & .94 & .75 & 1.03 & 2.22 & .97 & .68 & 3.82 & $7.2 \mathrm{I}$ & 27.77 & 3.19 & 3.43 & .24 \\
\hline Z. M. APPLE. & 1.0 & .86 & I.04 & 1.07 & 1. Io & $\mathrm{r} .2 \mathrm{I}$ & 2.94 & I. $3^{8}$ & .93 & .76 & $\mathrm{I} .04$ & 2.01 & .86 & .93 & 3.18 & 3.25 & 23.56 & 2.89 & 3.06 & .17 \\
\hline Neldie Green. & 1.03 & $.8 \mathrm{I}$ & 1.03 & .96 & .92 & .96 & 2.57 & .96 & .85 & .88 & .99 & 2.12 & $.8 \mathrm{I}$ & .85 & 2.94 & 4.08 & 22.76 & 2.72 & 2.69 & .03 \\
\hline W. H. FoGG . & .66 & 1.13 & 1.17 & I. 13 & I. 17 & 1.17 & 2.72 & 1.83 & .89 & I. 17 & $I .32$ & 2.22 & $\cdot 78$ & 1.05 & 3.66 & 3.15 & 25.22 & 2.57 & 2.69 & .12 \\
\hline E. B. C CASSELL & .92 & 1.10 & I. 10 & 1.03 & .96 & 1.07 & 2.54 & 2.35 & .88 & 1.07 & I.10 & 2.09 & 1.03 & .92 & $3 \cdot 31$ & 5.22 & 26.69 & 2.72 & 2.76 & .04 \\
\hline C. W. GoodMAN & .92 & .62 & I. 10 & .92 & 1.03 & .92 & 2.46 & I.69 & .82 & 1. 10 & I. 10 & 2.28 & 1.03 & .88 & 2.64 & 3.71 & 23.22 & 2.72 & 2.78 & .06 \\
\hline H. O. Chapman & 1.05 & .98 & I. 12 & 1.05 & 1.22 & .98 & 2.44 & I. 74 & .77 & .94 & 1.05 & 2.44 & .80 & .84 & 2.86 & 4.18 & 24.46 & $\begin{array}{l}2.87 \\
\text { Av. }\end{array}$ & $\begin{array}{l}3.02 \\
\text { Av. }\end{array}$ & .15 \\
\hline Ineal & 1.00 & 1.00 & 1.00 & 1.0 & 1.00 & 1.00 & 3.00 & 3.00 & $1 . \infty$ & 1.00 & 1.00 & 3.00 & $1 . \infty$ & $1 . \infty$ & 3.00 & 6.00 & 29.00 & 2.80 & 2.92 & .12 \\
\hline
\end{tabular}


TABLE III.

\begin{tabular}{|c|c|c|c|c|c|c|c|c|c|c|c|c|c|c|c|c|c|c|c|c|}
\hline No. & & A & C & $\stackrel{A}{\bullet}$ & C & $\stackrel{A}{ }$ & C & $\underline{B}$ & $E$ & $\stackrel{A}{\circ}$ & C & $\mathbf{A}$ & E & $\stackrel{A}{\circ}$ & C & $\underline{\mathbf{B}}$ & $\mathbf{F}$ & T'T'L. & $\begin{array}{l}\text { Av. } \\
\text { Dot. }\end{array}$ & $\begin{array}{l}\text { IDENTI- } \\
\text { FIED AS }\end{array}$ \\
\hline $\mathbf{I}$ & $\begin{array}{l}\text { (a) } \\
\text { (b) }\end{array}$ & $\begin{array}{l}.51 \\
.66\end{array}$ & $\begin{array}{l}\text { I. } 15 \\
\text { I. } 13\end{array}$ & $\begin{array}{l}\text { I. } 15 \\
\text { I.17 }\end{array}$ & $\begin{array}{l}\text { I. } 15 \\
\text { I. } 13\end{array}$ & $\begin{array}{l}1.15 \\
1.17\end{array}$ & $\begin{array}{l}\text { I.15 } \\
\text { I.17 }\end{array}$ & $\begin{array}{l}2.70 \\
2.72\end{array}$ & $\begin{array}{l}1.74 \\
1.83\end{array}$ & $\begin{array}{l}.97 \\
.89\end{array}$ & $\begin{array}{l}1.15 \\
\text { I. } 17\end{array}$ & $\begin{array}{l}\mathrm{I} .35 \\
\mathrm{I} .32\end{array}$ & $\begin{array}{l}2.30 \\
2.22\end{array}$ & $\begin{array}{l}.77 \\
.78\end{array}$ & $\begin{array}{r}.97 \\
1.05\end{array}$ & $\begin{array}{l}3.67 \\
3.66\end{array}$ & $\begin{array}{l}3.09 \\
3.15\end{array}$ & $\begin{array}{l}24.97 \\
25.22\end{array}$ & $\begin{array}{l}2.59 \\
2.57\end{array}$ & W. H. F. \\
\hline 2 & $\begin{array}{l}\text { (a) } \\
\text { (b) }\end{array}$ & $\begin{array}{l}.93 \\
.96\end{array}$ & $\begin{array}{l}.93 \\
.99\end{array}$ & $\begin{array}{l}1.23 \\
\mathrm{I} .21\end{array}$ & $\begin{array}{l}1.08 \\
1.02\end{array}$ & $\begin{array}{l}1.08 \\
1.11\end{array}$ & $\begin{array}{l}\mathrm{I} .23 \\
\mathrm{I} .2 \mathrm{I}\end{array}$ & $\begin{array}{l}2.82 \\
2.82\end{array}$ & $\begin{array}{l}.93 \\
.96\end{array}$ & $\begin{array}{l}1.08 \\
1.05\end{array}$ & $\begin{array}{r}.93 \\
1.08\end{array}$ & $\begin{array}{l}1.08 \\
1.08\end{array}$ & $\begin{array}{l}\mathrm{I} .48 \\
\mathrm{I} .48\end{array}$ & $\begin{array}{l}.61 \\
.59\end{array}$ & $\begin{array}{l}1.08 \\
1.11\end{array}$ & $\begin{array}{l}4.6 I \\
437\end{array}$ & $\begin{array}{l}4 \cdot 3 I \\
4 \cdot 3 I\end{array}$ & $\begin{array}{l}25 \cdot 37 \\
25 \cdot 35\end{array}$ & $\begin{array}{l}3.25 \\
3.23\end{array}$ & C. I. B. \\
\hline 3 & $\begin{array}{l}\text { (a) } \\
\text { (b) }\end{array}$ & \begin{tabular}{|c}
.99 \\
1.03
\end{tabular} & $\begin{array}{l}.78 \\
.8 \mathrm{I}\end{array}$ & $\begin{array}{l}1.07 \\
1.03\end{array}$ & $\begin{array}{l}.99 \\
.96\end{array}$ & $\begin{array}{l}.99 \\
.92\end{array}$ & $\begin{array}{l}.96 \\
.96\end{array}$ & $\begin{array}{l}2.54 \\
2.57\end{array}$ & $\begin{array}{l}.99 \\
.96\end{array}$ & $\begin{array}{l}.88 \\
.85\end{array}$ & $\begin{array}{l}.99 \\
.88\end{array}$ & $\begin{array}{l}.99 \\
.99\end{array}$ & $\begin{array}{l}2.1 \mathrm{I} \\
2.12\end{array}$ & $\begin{array}{l}.78 \\
.8 \mathrm{I}\end{array}$ & $\begin{array}{l}.99 \\
.85\end{array}$ & $\begin{array}{l}3.09 \\
2.94\end{array}$ & $\begin{array}{l}4.10 \\
4.08\end{array}$ & $\begin{array}{l}23.27 \\
22.76\end{array}$ & $\begin{array}{l}2.56 \\
2.72\end{array}$ & N. G. \\
\hline 4 & $\begin{array}{l}\text { (a) } \\
\text { (b) }\end{array}$ & $\begin{array}{l}.92 \\
.91\end{array}$ & $\begin{array}{l}\text { I.12 } \\
\text { I.16 }\end{array}$ & $\begin{array}{l}x .18 \\
1.19\end{array}$ & $\begin{array}{l}1.12 \\
1.03\end{array}$ & $\begin{array}{l}1.28 \\
1.23\end{array}$ & $\begin{array}{l}1.12 \\
1.03\end{array}$ & $\begin{array}{l}2.6 \mathrm{I} \\
2.8 \mathrm{I}\end{array}$ & $\begin{array}{l}2.04 \\
2.08\end{array}$ & $\begin{array}{l}.92 \\
.9 \mathrm{I}\end{array}$ & $\begin{array}{l}1.28 \\
1.30\end{array}$ & $\begin{array}{r}.92 \\
1.04\end{array}$ & $\begin{array}{l}2.6 \pi \\
2.80\end{array}$ & $\begin{array}{l}.74 \\
.68\end{array}$ & $\begin{array}{r}.92 \\
I .01\end{array}$ & $\begin{array}{l}3.33 \\
3.43\end{array}$ & $\begin{array}{l}5.42 \\
6.54\end{array}$ & $\begin{array}{l}27.53 \\
29.15\end{array}$ & $\begin{array}{l}2.67 \\
3.07\end{array}$ & G. W. D. \\
\hline 5 & $\begin{array}{l}\text { (a) } \\
\text { (b) }\end{array}$ & $\begin{array}{l}.94 \\
.92\end{array}$ & $\begin{array}{l}.94 \\
.95\end{array}$ & $\begin{array}{l}.94 \\
.95\end{array}$ & $\begin{array}{l}.94 \\
.95\end{array}$ & $\begin{array}{l}1.10 \\
1.10\end{array}$ & $\begin{array}{l}.79 \\
.83\end{array}$ & $\begin{array}{l}2.36 \\
2.3^{8}\end{array}$ & $\begin{array}{l}\text { I.10 } \\
\text { r.10 }\end{array}$ & $\begin{array}{l}.94 \\
.89\end{array}$ & $\begin{array}{l}.84 \\
.86\end{array}$ & $\begin{array}{l}1.10 \\
1.19\end{array}$ & $\begin{array}{l}2.05 \\
2.09\end{array}$ & $\begin{array}{l}.94 \\
.92\end{array}$ & $\begin{array}{l}.74 \\
.74\end{array}$ & $\begin{array}{l}2.66 \\
2.69\end{array}$ & $\begin{array}{l}3.95 \\
4.09\end{array}$ & $\begin{array}{l}22.33 \\
22.65\end{array}$ & $\begin{array}{l}3.17 \\
3.35\end{array}$ & A. H. G. \\
\hline 6 & $\begin{array}{l}\text { (a) } \\
\text { (b) }\end{array}$ & $\begin{array}{r}1.00 \\
.95\end{array}$ & $\begin{array}{l}.75 \\
.86\end{array}$ & $\begin{array}{r}1.00 \\
.90\end{array}$ & $\begin{array}{l}.75 \\
.72\end{array}$ & $\begin{array}{l}.75 \\
.90\end{array}$ & $\begin{array}{r}1.00 \\
.99\end{array}$ & $\begin{array}{l}2.50 \\
2.52\end{array}$ & $\begin{array}{l}1.25 \\
1.44\end{array}$ & $\begin{array}{l}1.00 \\
1.12\end{array}$ & $\begin{array}{l}1.00 \\
1.04\end{array}$ & $\begin{array}{l}1.25 \\
1.22\end{array}$ & $\begin{array}{l}2.25 \\
2.25\end{array}$ & $\begin{array}{r}1 . \infty \\
.90\end{array}$ & $\begin{array}{r}\mathrm{I} .00 \\
.95\end{array}$ & $\begin{array}{l}3.00 \\
3 \text { II }\end{array}$ & $\begin{array}{l}3.00 \\
2.93\end{array}$ & $\begin{array}{l}22.50 \\
22.80\end{array}$ & $\begin{array}{l}2.00 \\
2.22\end{array}$ & A. B, E. \\
\hline
\end{tabular}

(a). The unknown record given in terms of $\mathrm{mm}$. reduced to per cents. of the average of the six dots contained in it, as in Table II.

(b). A row of per cents. from Table II, selected as representing the unknown sender, because of its greater resemblance to (a). The letters A, B, C, etc., refer to the several Morse characters. 
computed as above. The identification was equally sure. Table III. gives the six sets of results obtained in this way in comparison with the corresponding results from Table II. Of special importance is the fact that the individual results, numbers four, five and six, Table III., were written much more swiftly than the results represented in Table II. by the same operators; for it is thus shown that the individual characteristics persist through different rates of speed. The variation in speed does not, however, leave the ratios between the several characters undisturbed. Examination of Table III. will show that greater speed is gained for the most part by shortening the longer characters. Fig. I in Plate I. shows the relations of Table III. graphically.

Third treatment.-By a different method, a single letter $v$

TABLE IV.

\begin{tabular}{|c|c|c|c|c|c|c|c|c|c|c|}
\hline OPERATOR. & & $\stackrel{A}{?}$ & C & A & $\mathrm{C}$ & A & C & B & $\mathbf{E}$ & Total. \\
\hline \multirow{2}{*}{ H. O. C. } & (a) & .099 & $\infty 93$ & .105 & .099 & .116 & .092 & $.23 I$ & .165 & 1.000 \\
\hline & (b) & .098 & .094 & .105 & .098 & .116 & .094 & .230 & .165 & 1.000 \\
\hline \multirow{2}{*}{ G. H. G. } & (a) & .101 & . $\mathrm{OOI}$ & . 105 & .105 &. $\mathrm{I} 2 \mathrm{I}$ &.$\infty 1$ & .258 & .118 & 1.000 \\
\hline & (b) & .097 & .097 & .104 & .106 & . II & .091 & .258 & .128 & 1.000 \\
\hline \multirow{2}{*}{ G. E. F. } & (a) & .063 & .073 & .059 & .076 & .055 & .054 & .236 & .384 & $1 . \infty \infty$ \\
\hline & (b) & .067 & .067 & .058 & .081 & .058 & .058 & .230 & $.38 x$ & 1.000 \\
\hline \multirow{2}{*}{ A. B. G. } & (a) & .067 & .114 & .060 & .109 & .042 & .126 & .265 & .217 & $1 . \infty 00$ \\
\hline & (b) & .069 & .118 & .063 & .105 & .043 & .128 & .260 & .24 & 1.000 \\
\hline \multirow{2}{*}{ N. G. } & (a) &.$I I I$ & .093 & .111 & .102 & .100 & .105 & .275 & .103 & $1 . \infty 00$ \\
\hline & (b) & .114 & .089 & .112 & .1OI & .100 & .102 & .274 & .108 & 1.000 \\
\hline \multirow{2}{*}{ N. H. } & (a) & .065 & .899 & .10 & .089 & .109 &.$\infty 90$ & .248 & .210 & 1.000 \\
\hline & (b) & .063 & . & .100 & . & . Iro & .088 & .250 & .209 & 1.000 \\
\hline
\end{tabular}

(a) The ratios of the average length of each element, to the average length of the whole letter $v$.

(b) One of the eight percentages selected at random, the design being to demonstrate its efficiency in identification. 
from the word 'via' was studied. The average length of each element was found, and the ratio of this to the average length of the whole letter was computed. Each of the eight trials for six of the subjects chosen at random were thus treated. The results are given in Table IV., and they show that each of the six may be identified by the characteristics which appear in the single letter.

Variation:-Sixty-nine dots are required to write the message used. An operator wrote the message eight times. It is evident that the sixty-nine dots made in one writing of the message will vary, and also that each of the sixty-nine dots will vary in the eight successive writings thereof. To save circumlocutions, I shall call the first heterotaxic variation, and the second homotaxic variation. These two sorts of variation were studied in a variety of ways, covering all the material at disposal, and always with the same result. In order to make a sure, quantitative comparison between the two sorts of variation, it was decided to study eight dots, beginning with the first dot in the word 'via.' Since the message was written eight times, this selection gave eight rows and eight columns, or sixty-eight dots in all, for each of the sixteen subjects. The homotaxic variation was computed as follows: The average, the mean variation $\left(\frac{\sum v}{n}\right)$, and the per cent. which the latter is of the former were computed for each of the eight columms. The average of these eight results is a measure of the homotaxic variation. The heterotaxic variation was found by two methods. First, the rows were treated in the same manner as that used in finding the homotaxic variation in the columns. Second, the average of each column was found, and then the per cent. of variation in these averages was computed. The reason for this procedure will be given below. Table V. shows the results obtained.

It is evident from the foregoing table that the homotaxic variation is an inverse measure of skill. In every day language, this simply means that an operator can repeat the same action more exactly the more expert he is.

The heterotaxic variation as given in column II. is a resultant of two factors. First, of course, the accidental variation 
TABLE V.

\begin{tabular}{|c|c|c|c|c|c|}
\hline OPERATOR. & AGE. & $\begin{array}{c}\text { Years } \\
\text { Experience. }\end{array}$ & $\begin{array}{l}\text { Homo- } \\
\text { TAXIC I. }\end{array}$ & $\begin{array}{l}\text { HATERO- } \\
\text { TAXIC II. }\end{array}$ & $\begin{array}{l}\text { HETERO- } \\
\text { TAXIC III. }\end{array}$ \\
\hline C. G. Mallotte. . . & 22 & 2 & II 7 & .120 & .086 \\
\hline A. B. Guthrie . . . . & $2 \mathbf{I}$ & $5-12$ & .112 & $.16 \pi$ & .150 \\
\hline G. E. FyLLows . . . & 43 & ${ }^{2} 5$ & .094 & .097 & .035 \\
\hline G. W. DYER. . . . & 60 & 33 & .078 & .154 & .150 \\
\hline NeLlir Grien . . . & 24 & 5 & .075 & .156 &.$x_{50}$ \\
\hline C. L. Buchanan ... & 57 & 25 & .070 & .152 & .130 \\
\hline L. A. Cllark . . . & 40 & 17 & .062 & .078 & .053 \\
\hline Noble Harter $\cdots$ & 37 & $2 I$ & .056 & .171 & .170 \\
\hline R. C. BROOKS . . . & $2 \mathrm{I}$ & 3 & .052 & .135 & .120 \\
\hline Z. M. Apple . . . & 24 & 5 & .050 & .090 & .072 \\
\hline A. B. Evans . . . & 27 & 10 & .047 & .170 & .170 \\
\hline C. W. Goodman . . . & 32 & 15 & .045 & .104 & .088 \\
\hline H. O. Chapman ... & 27 & IO & .045 & .116 & .083 \\
\hline G. H. GODFREY & 55 & $3 I$ & $.04 r$ & .120 & .106 \\
\hline W. H. JOGG. . . . & 26 & 10 & .034 & .192 & .180 \\
\hline E. B. Cassell. . & 36 & 18 & .027 & .092 & .075 \\
\hline
\end{tabular}

enters here as everywhere. Second, the operator does not intond to make the same character exactly alike in successive positions. This intentional differentiation corresponds to inflection in speech. A study of Table II. or III. will show clearly these characteristic differences between a character in one position and the same character in a different position. By computing the heterotaxic variation by the second method described, we partially eliminate the element of accidental variation. A comparison of the variations given in columns II. and III. of Table $V$. shows that the amount of accidental variation thus eliminated is, as might be expected, smaller in the case of the expert men. If we take the results in column III., Table $V$. as the best attainable measure of variation due to intentional inflection, it appears that this is slightly greater in the more expert men than in the less expert. The average heterotaxic

1 Has been out of business about 18 years. 
variation of the first seven, or the less expert operators, as determined from column III. of Table V. is ro6. The corresponding value for the last nine, the more expert men, is $\mathrm{I}$ I8. The largest two values in the Table belong to two of the more expert men, and the smallest two belong to two of the less expert men.

In conclusion, therefore, it may be said that the accidental variation is a somewhat accurate inverse measure of skill, while the variation for inflection, is likely to be larger rather than smaller with increasing expertness.

Note on the accuracy with which the longer groups of clicks are made by telegraphic operators. A count of the results show in writing.

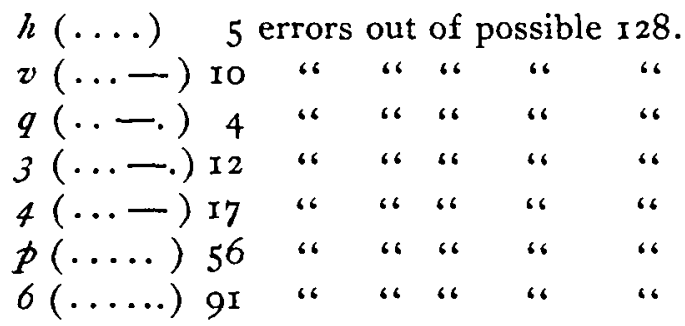

In order to show the variations in writing the figure 6 $(\ldots \ldots)$, and that these variations are not primarily determined by the skill of the operator, the results for the several operators are given.

V. The Curves of Improvement in Receiving AND SENDING.

Throughout the year of exploration, operators were questioned closely with regard to the rate of improvement with practice at various periods. Operators generally agreed upon certain main facts. Upon the basis of this general inquiry and of his own personal experience as an operator and a teacher of telegraphy, $\mathrm{H}$. drew the curves represented in Fig. II., Plate I. as a rough picture of the facts.

In further verification of the main characteristics of these curves over two hundred operators, ranging in skill from the 


\begin{tabular}{|c|c|c|c|}
\hline OpERATORs. & YeARS EXPERIENCE. & Prasent Position. & $\begin{array}{l}\text { Av. No. of Dots } \\
\text { IN WRITING } 6 .\end{array}$ \\
\hline$C G M$ & 2 & Student & 5.2 \\
\hline$A B G$ & $5-12$ & “ & 6.0 \\
\hline GE F & 5 & College Professor & 5.6 \\
\hline GW D & 33 & Ry. Agent & 9.2 \\
\hline NG & 5 & Ry. Operator & 10.2 \\
\hline$C \perp B$ & 25 & Ry. Agent & 8.6 \\
\hline L A C & 17 & $" 6$ & 6.1 \\
\hline N H & $2 \mathbf{I}$ & Teacher & 7.5 \\
\hline R C B & 3 & Student & $7 \cdot 1$ \\
\hline$Z \mathbf{M} \mathbf{A}$ & 5 & W. U. Operator & 6.0 \\
\hline A B E & 10 & " $"$ & 7.2 \\
\hline C W G & I5 & Dispatcher & $6 . \mathrm{I}$ \\
\hline $\mathrm{HOC}$ & ro & “ & 7.7 \\
\hline G H G & $3 \mathrm{I}$ & Ry. Agent & 12.2 \\
\hline$W H F$ & I0 & Dispatcher & 5.0 \\
\hline R B C & 18 & " & 8.7 \\
\hline
\end{tabular}

most expert to those just beginning, have been questioned and have given practically unanimous assent. ${ }^{1}$

For the purpose of gaining not only more, but more definite information, requests were sent to a number of schools of telegraphy. Blanks were sent to such schools with the request that the typical curves of improvement be plotted. In many cases, of course, no reply was received, and in some cases the advertising impulse was the evident inspiration of curves which represented their students as becoming skillful operators in a few months. The manager of Valentine's School of Telegraphy, Jonesville, Wis., wrote: "While I recognize the fact that every student undergoes the experience you have outlined in your letter, I hesitate to furnish you this information without first having systematically obtained it." Seven months later he sent the

${ }^{2}$ One skillful operator denied having experienced the period of non-advancement shown in the receiving curve before reaching the main-line rate. His associates in the office explained this exception as a lapse of memory due to vanity. Their incredulity illustrates the practical unanimity of opinion. 
curves in Fig. III., Plate I., which are believed to be entirely reliable, as is also Fig. IV., Plate I. from the Commercial College of Kentucky.

Two schools where telegraphy is taught in Cincinnati were visited personally and arrangements made to have the progress of a representative student in each observed systematically. These results are given in Figs. V. and VI., Plate I. Arrangements were also made to have two reputable operators, well known to $\mathrm{H}$., observe and test the progress of one student in each of their offices, from the time of beginning until proficiency was reached. These results are given in Figs. VII. and VIII., Plate I.

Finally $H$. was able, during the winter $95-96$, to test the advancement of two learners from the beginning until they were both fair operators. Both were students in the Western Union Office at Brookville, Indiana. The operator, Mr. Balsley gave every assistance in his power to make the investigation successful. Will J. Reynolds, one of the students, is eighteen years old and is a young man of more than ordinary ability. Edyth L. Balsley, the other student, is seventeen years old and is a very bright young girl. The former began in August, the latter in September, I895. The tests were made every Saturday. Forty tests were made with the young man and thirty-six with the young woman.

Ordinarily telegraphic speed is reckoned in terms of so many words per minute. For these tests, however, the letters were counted. Of course sentences were used in each test which had not been used before. Pains were taken to keep the tests of uniform difficulty. On the one hand, many short and easy combinations, and on the other hand, combinations representing unusual difficulty from a telegraphic point of view were avoided. Special pains were also taken to see that the amount of practice from week to week was substantially uniform.

The sending test was made as follows: The learner was directed to write as fast as he could do so, legibly. The observer copied the words as sent as a test of legibility. Some twominute period was noted by the observer, unknown to learner, and the number of letters sent in that time was afterward 
counted. Several tests were taken and the results averaged. The variation in the several tests was slight ${ }^{1}$. The receiving test was made as follows: The observer would try a rate of sending which he judged would correspond to the learner's capacity. The learner was required to name the letters, later on the words, or, when he had more skill, to copy without naming them. If he failed to interpret correctly at that rate, a slower rate was tried. If he succeeded, a more rapid rate was tried. A two-minute period was noted and the letters were counted as above.

The results of this study are shown in Figs. IX. and X. ${ }^{2}$

Significance of the practice curves. Certain main facts appear in all the foregoing curves:

I. The sending curve rises more rapidly and more uniformly than does the receiving curve from the beginning of practice to the learner's maximum ability.

2. The receiving curve rises more slowly and irregularly. All the results agree in showing a long, flat curve for several months before the slowest main-line rate is reached; and all the evidence before us indicates another long flat curve a little above the rate necessary for the transaction of ordinary office business, in the case of operators to whom that amount of skill in receiving is sufficient. A study of the quantitative results shown in Figs. IX. and X. shows that there are many short flat places in the receiving curve followed by relatively rapid improvement.

3. Two of the curves show a fact which usually appears at a period of the learner's development later than that shown in these curves, namely, that the receiving rate finally exceeds the sending rate. This is almost the universal rule. A receiving operator with a typewriter can practically take his ease in taking the most rapid press work.

1 The M. V. ranged from $37 \%$ to $2.3 \%$ of the averages.

${ }^{1}$ It is believed that the progress of the learners was materially hastened by their interest in the tests. They were forewarned as to the slowness of progress and they gave special attention to practice. Both are now (June 1896 ) able to transact ordinary business on the main line. It may prove to be worth while for certain purposes to study the curves of improvement with more accurate methods and apparatus, but there can be no doubt that the method used gives a highly accurate quantitative picture of these curves. 
Fic. IX.

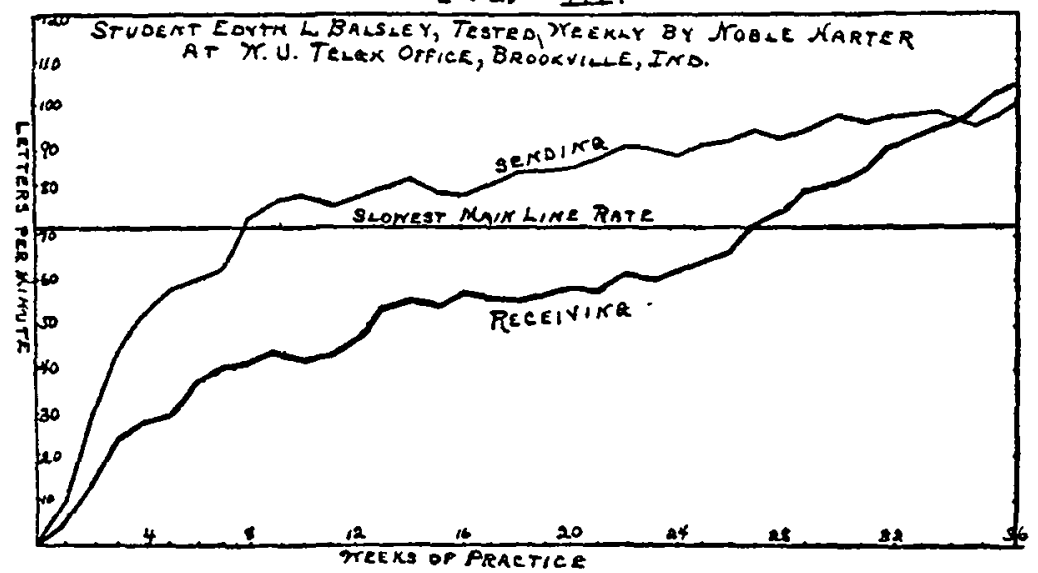

Fia. X

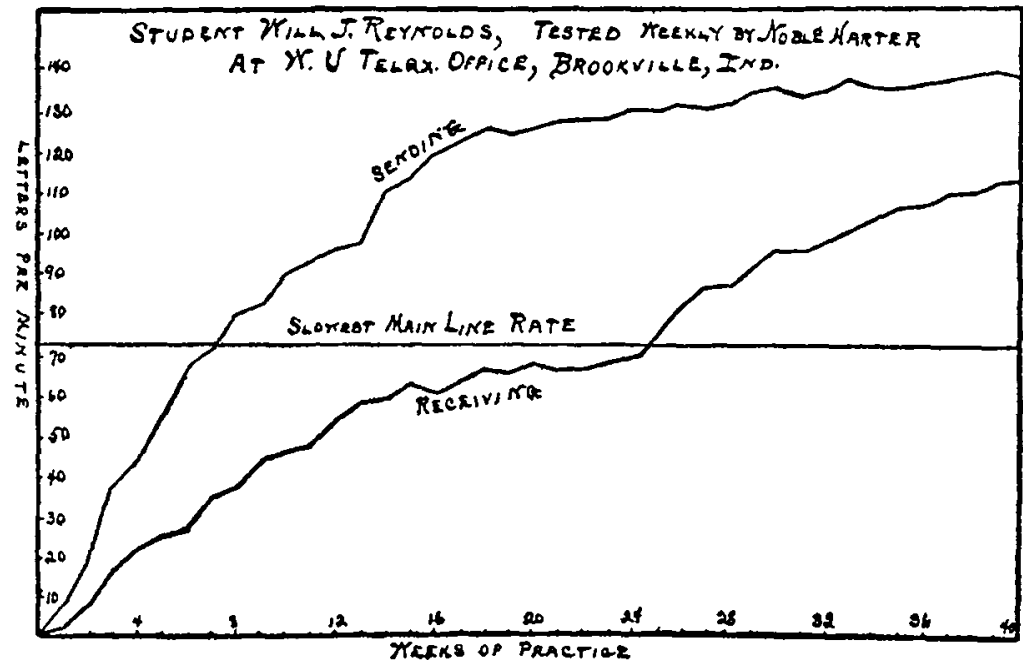

4. In considering the reasons for the remarkable differences between the receiving and sending curves, the following points may be noticed: (a) The language which comes to the ear of the learner seems to him far more complex than the language which he has to write. When he wishes to write the letter $e$, he must have in mind only the making of one quick snap with his hand. When he hears the letter $e$, he hears two sounds, 
the down stroke and the back stroke, and must take note of the time between them to distinguish the dot from the dash. If we take the more difficult combinations, as $k(-.-)$, or $j$ (-. -.), the greater complexity of the sound picture with its irregularly occurring back stroke is sufficiently evident. (b) The opportunity for practicing receiving at slow rates is evidently far less than for sending at such rates. It is always possible for the learner to do his slow best at sending, but he must depend upon others for a chance to receive at a rate within his capacity. It is of course true that he hears all that he himself sends, but it is a significant fact that the hearing of his own writing does not improve his power to receive in anything like the same degree that the hearing of other operators' writing does. As the curves show, young operators can, at a certain period, send with fair rapidity for a long period during which they cannot understand a single sentence on the main line. A further significant fact is that learners cnjoy the practice of sending, but feel practice in receiving to be painful and fatiguing drudgery. For this reason they naturally incline to practice sending a great deal, but must summon up all their resolutions to keep up the necessary practice in receiving. (d) A fact which seems to be highly significant is that years of daily practice in receiving at ordinary rates will not bring a man to his own maximum ability to receive. The proof of this fact is that men whose receiving curve has been upon a level for years frequently rise to a far higher rate when forced to do so in order to secure and hold a position requiring the higher skill. That daily practice in receiving will not assure improvement is further seen in the fact that in many cases inferior operators after being tolerated for years are finally dropped because they do not get far enough above the dead line. (e) One conclusion seems to stand out from all these facts more clearly than anything else, namely, that in learning to interpret the telegraphic language, it is intcnse effort zuhich educates. This seems to be true throughout the whole length of the curve. Every step in advance seems to cost as much as the former. Indeed, each new step seems to cost more than the former. Inquiry at the telegraph schools and among operators indicates that between sixty 
and seventy-five per cent. of those who begin the study of telegraphy become discouraged upon the plateau of the curve just below the main-line rate. As a rule, ordinary operators will not make the painful effort necessary to become experts. Facts of an analogous character will be recalled from other fields.

The physiological, psychological and pedagogical implications of this conclusion are manifestly important. If in our educational methods in the past, we have often made the pace that kills, there is possibly the danger on the other hand that we shall make school work all play, and so eliminate the intense effort which is necessary for progress. ${ }^{1}$

5. The sending curve conforms approximately to the wellknown typical practice curve with the important difference from the curves usually obtained in the laboratory that it extends over a much greater period of time. This difference characterizes the whole curve. If we represent the practice curve by the general equation

$$
y=f(x)
$$

it is evident that the function of $x$ contains a constant which depends upon the unit of time. So for example, the curve given in the figure would present exactly the same appearance if the same results had been obtained in forty successive hours or forty successive years. Comparison of different practice curves shows that this time factor varies greatly in the development of different abilities. A comparative study of this charac-

${ }^{1}$ The conclusion here reached in matters of learning telegraphy recalls the opinion of Senator Stanford upon the training of race horses. In a letter to Horace Busbey (Scribner's, June, '96), Senator Stanford says :

" My own idea, and I think it is justified by experience, is to commence working the colt early, developing its strength with its growth. If the exercise is judicious, the colt takes no harm from it. I do not remember a single instance where an animal of mine was injured by early work. When a breakdown has occurred, it has been invariably after a let-up. Let-ups are very dangerous to young fast animals, as their bodies grow during the let-up without corresponding development of strength, and they are very liable to get too much work when their exercise is renewed. My aim is to give the greatest amount of exercise without fatigue, and never to allow it to reach the period of exhaustion. This is secured by short-distance exercise. It is the supreme effort tha develops. If colts are never over-worked they are always willing to try in thei exercise, having no apprehension that they will be forced beyond their comfort." 
teristic of various practice curves would have evident theoretical and practical values.

6. The receiving curve presents many profound interests and difficulties. It is a quantitative study of apperception. It represents with a high degree of accuracy the increasing power which practice brings to interpret a language. The task of the mind is not in every respect analogous to that involved in listening to foreign speech, for in the telegraphic language, after a short time, every element is recognized by the learner if he is given time, whereas in the foreign speech he may frequently be disturbed by words that are entirely unknown. We have, however, gained the impression, partly from personal experience and partly from conversation with teachers of language and others who have learned foreign languages, that the curve of practice in learning a language must present at least great general similarities to the receiving curves here shown. All agree that just below the ability to understand what is spoken, there is a long discouraging plateau where many give up in despair; that there is at last a sudden ascent into the ability to understand most of what is said; finally that the perfect mastery of one at home in the language, comes much later and only after very persistent work. Of those who undertake the study of any foreign language, most stop on the first plateau below a working proficiency; and of those who go on, most stop on the second plateau, below complete mastery.

7. What is the interpretation of the plateaus in the receiving curve? For many weeks there is an improvement which the student can feel sure of and which is proved by objective tests. Then follows a long period when the student can feel no improvement, and when objective tests show little or none. At the last end of the plateau the messages on the main line are, according to the unanimous testimony of all who have experience in the matter, a senseless clatter to the student-practically as unintelligible as the same messages were months before.

1 The President of the Cincinnati Business College, who prepared estimate VI., says that the same general characteristics appear in the learning of shorthand. A director of primary work in a western city, after examining the receiving curve, expresses the opinion that it represents the progress of a child in learning to read. This point will be made a subject of immediate investigation. 
Suddenly, within a few days, the change comes, and the senseless clatter becomes intelligible speech.

In explanation of the form of the motor curve, one may suppose that it is an asymptotic approach to a physiological limit. In the receiving curve there is also something like an asymptotic approach to a limit; but that limit, whatever its nature, suddenly disappears. What it is that occurs during the period of sensible and measurable improvement, may be represented in various ways according to the standpoint from which the mind and mental growth are viewed. But in every case, one has to account for the great slowing down in the process of improvement. Stated otherwise, the task is to explain the nature of the changes in brain or mind which must be taking place, during the period represented by the plateau, and which yet make no determinable manifestation of themselves. That changes are taking place during this period, which are essential to the acquisition of proficiency, is proved by the fact that no one is able to omit this period.

8. As suggested above, it is probable that the curves which represent the acquisition of the telegraphic language also represent the main characteristics of the curves for many other acquisitions. This should, however, by no means be taken for granted. We should rather require of ourselves a thorough study of the actual curves of improvement for every ability which makes measurable manifestation of itself. The determination and comparative study of these curves would furnish one thing which is always a precious enlargement to any sciencean outlay of problems which permit approach by systematic research and which promise results of far-reaching, theoretical and practical importance. 